COLLOQUE DE PHYSIQUE

Colloque C5, supplément au $\mathrm{n}^{\circ} 18$, Tome 51 , 15 septembre 1990

\title{
MODELLING OF HIGH INTENSITY ARCS INCLUDING A NON-EQUILIBRIUM DESCRIPTION OF THE CATHODE SHEATH
}

\author{
C. DELALONDRE and O. SIMONIN \\ Laboratoire National $\bar{a}$ 'Hydraulique E.D.F., 6 quai Watier, 78400 \\ Chatou, France
}

Résumé : Un modèle a été développé pour la prediction d'arcs électriques à forte intensité et à pression atmosphérique. Le code Mélodie (différences finies orthogonales) nous a permis de résoudre le système couplé d'équations thermodynamiques et électromagnétiques incluant effet JOULE et forces de LORENTZ. Dans la colonne d'arc laminaire, les équations sont écrites en hypothèse d'équilibre thermodynamique local (E.T.L.), et avec l'approximation de la loi d'OHM. Les conditions aux limites à la cathode sont déterminées à partir d'un modele mono-dimensionnel de couche limite cathodique en déséquilibre thermodynamique, couplé de plus avec le calcul du transfert thermique dans l'électrode solide. Les calculs menés dans le cas d'arcs libres ou d'arcs tranférés dans l'argon, avec une cathode conique en tungstène, ont montré un bon accord avec les mesures.

Abstract : An axisymetric model has been developed for prediction of high intensity electric arcs under atmospheric pressure. A set of thermodynamic and electromagnetic equations, including interaction terms (JOULE effect, LORENTZ forces) is solved using the orthogonal finite difference numerical code Mélodie. Conservation equations in the laminar arc column (mass, momentum, energy and current) are written according to the local thermodynamic equilibrium (L.T.E.) assumption and the OHM law approximation. The proper boundary condition at the cathode is derived from a onedimensional description of non-equilibrium electrode boundary layer, coupled with full computation of heat transfer in solid region (conic cathode in tungsten). Numerical calculations performed for free burning and transferred argon arcs show a good agreement with experimental data.

\section{NOMENCLATURE}

$\alpha \quad$ subscript of the different specie of the

plasma [electrons e, atoms a, ions i]

$\vec{B}$ magnetic field (tesla $T$ )

$\mathrm{C}_{\mathrm{p}}$ plasma specific heat $\left(\mathrm{J} . \mathrm{kg}^{-1} . \mathrm{K}^{-1}\right)$

$\overrightarrow{\mathrm{E}} \quad$ electric field (Volts.m $\mathrm{m}^{-1}$ )

$E_{\text {io }}$ ionization energy of an atom $(J)$

$\vec{g} \quad$ gravity (m.s $\mathrm{s}^{-2}$ )

H plasma enthalpy (J.kg-1)

$\mathrm{I}_{\mathrm{e}}$ ionization/recombinaison reaction rate $\left(\mathrm{m}^{-3} \cdot \mathrm{s}^{-1}\right)$

$\vec{j} \quad$ total current density (A.m ${ }^{-2}$ )

$\overrightarrow{j_{\alpha}} \quad$ current density of $\alpha$ specie (A.m-2)

$\lambda$ plasma thermal conductivity $\left(\mathrm{W} \cdot \mathrm{m}^{-1} \cdot \mathrm{K}^{-1}\right)$

$\mathrm{n}_{\alpha} \quad$ number density of a particles $\left(\mathrm{m}^{-3}\right)$

$\mu \quad$ plasma dynamic viscosity $\left(\mathrm{kg} \cdot \mathrm{m}^{-1} \cdot \mathrm{s}^{-1}\right)$

Pot electric potential (Volts V)

p plasma density $\left(\mathrm{kg} \cdot \mathrm{m}^{-3}\right)$

$\mathrm{T}_{\alpha} \quad$ phase $\alpha$ temperature (Kelvins $\mathrm{K}$ )
T plasma temperature (K)

$\vec{\tau} \quad$ total stress tensor $\left(\mathrm{kg} \cdot \mathrm{m}^{-1} \cdot \mathrm{s}^{-2}\right)$

$\sigma \quad$ electric conductivity $\left(\mathrm{W}^{-1} \cdot \mathrm{m}^{-1}\right)$

$\overrightarrow{\mathrm{U}}$ plasma velocity (m.s $\mathrm{s}^{-\mathrm{l}}$ )

$\overrightarrow{\mathrm{U}_{\alpha}}$ phase $\alpha$ velocity $\left(\mathrm{m} . \mathrm{s}^{-1}\right)$

$V_{\text {ext }}$ extraction potential of the cathode material (V)

$V_{\text {io ionization potential of an atom (V) }}$

\section{Constants}

e elementary charge $\left(=1,60210^{-19} \mathrm{C}\right)$

$\varepsilon_{0}$ permittivity $\left(=8,85410^{-12} \mathrm{~F} . \mathrm{m}^{-1}\right)$

h PLANCK constant $\left(=6,62610^{-34} \mathrm{~J} . \mathrm{K}^{-1}\right)$

kB BOLTZMANN constant $\left(=1,3810^{-23} \mathrm{~J} . \mathrm{K}^{-1}\right)$

$m_{i}=m_{a}=m_{L}:$ one ion or one atom mass

(for $\operatorname{argon}=6,6310^{-26} \mathrm{~kg}$ )

me one electron mass $\left(=9,110^{-31} \mathrm{~kg}\right)$ 


\section{INTRODUCTION}

Modelling of electric arcs in flow is of great interest for many industrial processes such as electric breakers, welding technics, electric arc furnace, electric burners, and chemical reactors.

Our first step in arc flows modelling /1/ consisted in a laminar high intensity free burning argon arc column calculation with an orthogonal finite difference code, solving both thermodynamic and electromagnetic equations with the assumption of local equilibrium (L.T.E.). These equations are coupled by JOULE effect and LORENTZ forces terms, and the OHM law approximation is assumed in the arc column. First computation results were compared to the previous works of HSU, ETEMADI and PFENDER /2/:good agreement was found with their temperature measurements and also with their numerical modelling. But predictions appeared to be strongly dependant of the cathode boundary conditions which are very important for the arc characterization (current density distribution, electric radius...). Thus we developed a subgrid model applied on each boundary node, coupled with the arc column computation, and taking into account the thermal non-equilibrium of the cathode sheath region. Heat transfer in the metallic cathode is also taken into account in this calculation.

The first part of this paper describes the arc column model. The one-dimensional non-equilibrium model is presented in the second part. Boundary conditions and numerical methods are shortly described in paragraphs 3 and 4. The results in argon at atmospheric pressure are presented in part 5 first for a free burning arc with a total current intensity of $200 \mathrm{~A}$ or $300 \mathrm{~A}$ and a distance cathode-anode of $1 \mathrm{~cm}$, and then for transferred arcs of $275 \mathrm{~A}$ (long of $2.73 \mathrm{~cm})$ and $280 \mathrm{~A}(5.06 \mathrm{~cm})$. The cathodes are conic and made of tungsten.

\section{1- MODELLING OF THE ARC COLUMN.}

Local Thermodynamic Equilibrium (L.T.E.) is satisfied in the arc column. The global electric neutrality is also assumed in the plasma. The plasma flow, induced by magnetic forces (LORENTZ) in the case of free burning arc $/ 3 /$, or imposed along the cathode of transferred arc, is laminar. So we can write the following set of equations, coming from the usual fluids mechanics equations and coupled with the electromagnetic equations.

(1) Mass conservation :

(2) Momentum conservation :

$$
\frac{\partial \rho}{\partial t}+\operatorname{div}(\rho \vec{U})=0
$$

$$
\rho \frac{\partial \vec{U}}{\partial t}+[\rho \vec{U} \cdot \overrightarrow{\operatorname{grad}}] \overrightarrow{\mathrm{U}}=-\overrightarrow{\operatorname{grad}} \mathrm{p}+\operatorname{div} \vec{\tau}+\rho \overrightarrow{\mathrm{g}}+\vec{j} \wedge \overrightarrow{\mathrm{B}}
$$

The last term of the right-hand side of this equation relates to the electromagnetic forces of LORENTZ which induce a plasma flow in the arc column. Gravity can in fact be neglected.

(3) Energy conservation :

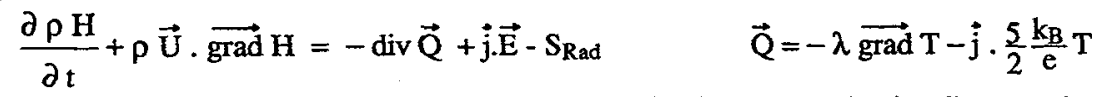

The first term of the right-hand side of this equation includes the thermal conduction flux and the transport of enthalpy by the electron gas. The second term is the JOULE heating. Then, we assume that the plasma is optically thin, so we introduce a global radiative dissipation $\mathrm{S}_{\mathrm{Rad}} / 4,5 /$.

(4) Current density conservation :

$$
\operatorname{div} \vec{j}=0
$$

which expresses the electric charge conservation in the assumption of plasma global neutrality.

(5) Ohm law :

$$
\vec{j}=\sigma \overrightarrow{\mathrm{E}}
$$

is considered to be available in the arc column. $\sigma$ is the electrical conductivity of argon given in function of the local temperature, as well as the over thermodynamic and transport properties $/ 6,7,8,9 \%$.

(6) Equation for electric potential :

MAXWELL equations give us the relation between electric field and potential :

$$
\vec{E}=-\overrightarrow{\operatorname{grad}}(\text { Pot })
$$

Finally, the magnetic field $\vec{B}$ is calculated from the current density $\vec{j}$ by the AMPERE theorem.

\section{2- MODELLING OF THE CATHODE SHEATH REGION}

To obtain accurate cathode boundary conditions for the global elliptic computation, we solve the general set of thermodynamic and electromagnetic equations written for non-equilibrium electrode boundary layer between each cathode wall node $P$ and its first neighboring node $M$ located inside the computational domain [fig. 1]. 
This local computation induce flux boundary conditions for the arc column calculation, but also for the heat transfer calculation in the cathode.
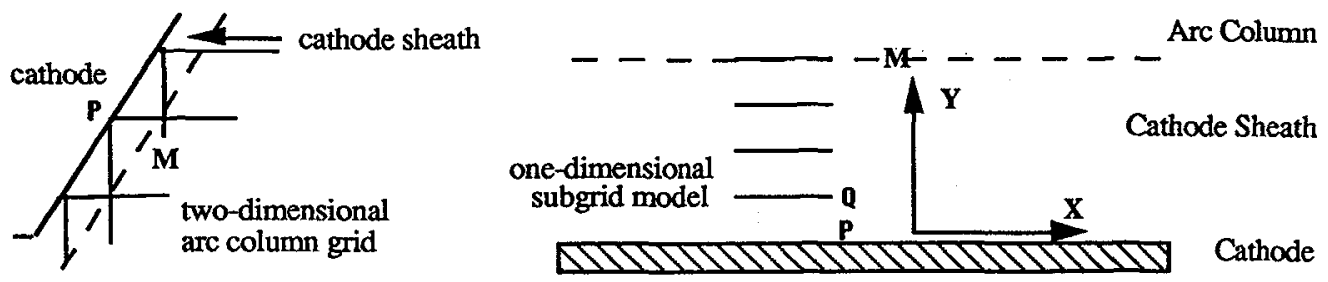

figure 1: Cathode sheath location and subgrid model description.

Because of the high temperature gradient, L.T.E. can not be used anymore near the electrode walls. Previous works $/ 10,11,12,13,14$ / showed that the plasma can be considered as a multiphase flow, where L.T.E. can be assumed in each phase. In argon plasma three phases are defined : the free electrons, the ions, and the atoms. Each specie $\alpha(=a, i, e)$ is in L.T.E. at the temperature $T_{\alpha}$, but according to collisional processes, atoms and ions seem to be in L.T.E. at $T_{L}$. The global neutrality of the plasma is always assumed. This model do not include the simulation of the space charge zone which takes place just close to the electrode at a scale lower than the mean free path of electrical charges and where global neutrality is not necessary verified.

Close to the cathode wall, the basic assumption is that advection terms as well as diffusion terms, in the direction parallel to the wall are negligible with respect to the corresponding terms in the direction perpendicular. With the previous assumptions, the general set of thermodynamic and electromagnetic non-equilibrium equations reduce to the following one-dimensional set $/ 15,16,17 /$ :

(1) Number densities particles conservation equations :

$$
\frac{\partial \mathrm{n}_{e}}{\partial \mathrm{t}}-\frac{1}{\mathrm{e}} \frac{\partial \mathrm{j}_{\mathrm{ey}}}{\partial \mathrm{y}}=\mathrm{I}_{\mathrm{e}}
$$

is the electron number density conservation law with the definition of the current density : $\vec{j}{ }_{e}=-n_{e} e \vec{U}_{e}$ The production rate of electron $\mathrm{I}_{e}$ is given by :

$$
I_{e}=k_{r e}\left(T_{e}\right) n_{e}\left[K_{6 q}\left(T_{e}\right) n_{a}-n_{e} n_{i}\right]
$$

where $\mathrm{k}_{\mathrm{re}}$ the ionization reaction rate has been taken from /17/, and supposed a three body recombinaison of argon. $K_{e q}$ the chemical equilibrium constant is given by the SAHA law $18,13,19,20 \%$.

Because of global neutrality we don't have to solve the ions number density conservation law, we have :

$$
n_{i}=n_{e}
$$

$\mathrm{n}_{\mathrm{a}}$ the atoms number density is deduced from the pressure which is supposed to be constant in the sheath:

(2) Generalized 'OHM law' :

$$
\mathrm{n}_{\mathfrak{a}}=\frac{\mathrm{p}}{\mathrm{k}_{\mathrm{B}} \mathrm{T}_{\mathrm{L}}}-\mathrm{n}_{\mathrm{e}}\left(1+\frac{\mathrm{T}_{\mathrm{e}}}{\mathrm{T}_{\mathrm{L}}}\right)
$$

In the cathode sheath the plasma isn't homogeneous and the ohmic conductor model is insufficient to predict the total current density $\vec{j}=\overrightarrow{j_{e}}+\overrightarrow{j_{i}}$. A diffusive contribution must be taken into account in both electronic and ionic current densities. With the following assumptions, total mass flux is equal to 0 , electron velocity is much greater than atoms or ions velocities, the current densities can be written :

$$
\begin{array}{lll}
j_{e y}=\sigma_{e} E_{y}+\frac{\sigma_{e}}{n_{e} e} \frac{\partial n_{e} k_{B} T_{e}}{\partial y} & \text { where: } & \sigma_{e}=\left(\frac{\pi}{8 k_{B} T_{e} m_{e}}\right)^{\frac{1}{2}} \frac{n_{e} e^{2}}{\left(n_{i} Q_{e i}+n_{a} Q_{e a}\right)} \\
j_{i y}=\sigma_{i} E_{y}-\frac{\sigma_{i}}{n_{i} e} \frac{\partial n_{i} k_{B} T_{L}}{\partial y}-\frac{\sigma_{i}}{\sigma_{e i}} j_{e y} & \text { where: } & \sigma_{i}=\left(\frac{\pi}{4 k_{B} T_{L} m_{L}}\right)^{\frac{1}{2}} \frac{n_{i} e^{2}}{\left(n_{i}+n_{a}\right) Q_{a i}} \\
\sigma_{e i}=\left(\frac{\pi}{8 k_{B} T_{e} m_{e}}\right)^{\frac{1}{2}} \frac{n_{e} e^{2}}{n_{i} Q_{e i}}
\end{array}
$$

$Q_{e i}, Q_{e a}, Q_{a i}$ are the electrons-ions, electrons-atoms and atoms-ions momentum-transfer cross sections calculated by DEVOTO /6/. With the assumption of a constant total current density we can eliminate the electric field in the current densities expressions and use the new expression of jey to solve the electrons density 
equation. Finally to determine $n_{e}, n_{i}, n_{a}, j_{e y}, j_{i y}$ and $E_{y}$, we only have to compute the $n_{e}$ conservation law. The electric potential is determined from the electric field.

\section{(3) Temperatures equations :}

These equations come from the enthalpy conservation law of each specie.

For the electrons temperature we have :

$$
\frac{5}{2} k_{B} n_{e} \frac{\partial T_{e}}{\partial t}+\frac{5}{2}\left(\frac{k_{B}}{-e}\right) j_{e y} \frac{\partial T_{e}}{\partial y}=\frac{\partial}{\partial y}\left(\lambda_{e} \frac{\partial T_{e}}{\partial y}\right)+j_{e y} E_{y}-E_{c o l l}-S_{R a d}-I_{e}\left[E_{i o}-\frac{5}{2} k_{B} \omega_{e}\left(T_{L}-T_{e}\right)\right]
$$

In this equation, the electron velocity is expressed in function of the current density. The first term on the righthand side is the thermal translational conductive flux for the electrons gas only: The second term is JOULE heating, it represents most of the electric energy transferred into heat to the plasma. The electrons exchange most of their energy with the heavy particles by elastic collisions represented by $\mathrm{E}_{\text {coll }} / 10,13 /$ which satisfies :

$$
E_{\text {coll }}=E_{\text {coll }(L)}=-E_{\text {coll }(e)}=n_{e}\left(n_{i} Q_{e i}+n_{a} Q_{e a}\right) \sqrt{\frac{8 k_{B} T_{e}}{\pi m_{e}}} \frac{2 m_{e}}{m_{i}} \frac{3}{2} k_{B}\left(T_{e}-T_{L}\right)
$$

Total radiative dissipation and energy transfer during ionisation/recombinaison (the last term on the right-hand side) are supposed to be mainly given by the electrons. The term in factor of $\omega_{\mathrm{e}}$ represents the thermalisation (at $\mathrm{T}_{e}$ ) of electrons emitted from the atoms at the temperature $\mathrm{T}_{\mathrm{L}}\left(\omega_{e}=0\right.$ if $\mathrm{I}_{\mathrm{e}}<0$ and $\omega_{e}=1$ if $\left.\mathrm{I}_{e}>0\right) / 16,17 /$. For the heavy particles temperature, if the total mass flux is neglected, the enthalpy conservation law gives :

$$
\frac{5}{2} k_{B}\left(n_{a}+n_{i}\right) \frac{\partial T_{L}}{\partial t}=\frac{\partial}{\partial y}\left(\lambda_{L} \frac{\partial T_{L}}{\partial y}\right)+j_{i y} E_{y}+E_{c o l l}-I_{e}\left[\frac{5}{2} k_{B} T_{e}+\frac{5}{2} k_{B} \omega_{e}\left(T_{L}-T_{e}\right)\right]
$$

\section{3- BOUNDARY CONDITIONS.}

(1) Subgrid model boundary conditions :

For $M$ points [fig. 1], we take the results of the arc column calculation :

$$
\mathrm{Te}(\mathrm{M})=\mathrm{TL}(\mathrm{M})=\mathrm{T} \text { column } \quad \mathrm{n}_{\mathrm{e}}(\mathrm{M})=\mathrm{f}\left(\mathrm{P}_{\text {column }}, \mathrm{T}_{\text {column }}, \mathrm{K}_{\mathrm{iq}}\right) \quad|\mathrm{j}|(\mathrm{M})=|\vec{j}|_{\text {column }}
$$

The wall boundary conditions are defined in $Q$ instead of $P$ [fig. 1] to take into account the space charge sheath $/ 10,12 /$ : the last mesh $P Q$ of the local one-dimensional computation is of the order of the mean free path of charges and represents the collisionless and space charge zone. Then if we assume that current densities are constant at that scale, and that ionic current density is defined by ions thermal agitation velocity, we can deduced a wall boundary condition for the electrons number density equation. We also verify that $j$ is lower than the maximum value given by thermo-electronic RICHARDSON-DUSHMANN (RD) emission $19 \%$.

Temperature continuity occures at the scale of particles mean free path, heavy particles and electrons temperatures conditions are written :

$$
T_{\mathcal{L}}(\mathrm{Q})=\mathrm{T}_{\text {cathode }}(\mathrm{P})
$$

$$
\left(\frac{\partial T_{e}}{\partial y}\right)_{Q}=0
$$

(2) Cathode boundary conditions :

At the top of the cathode, the temperature is given by experimental results $(1000 \mathrm{~K})$.

On the wall nodes $(\mathrm{P})$ the temperature is given by a flux continuity condition :

$$
\left(\lambda_{\text {cathode }} \frac{\partial T_{\text {cathode }}}{\partial y}\right)_{P}=V_{\text {cat }} \cdot\left|j_{i} y_{Q}+V_{\text {io }} \cdot\right| j_{i} y_{Q}-V_{\text {ext }} \cdot|j|
$$

Electrode heat conduction is balanced by energy sink terms due to heavy particles (when ions collide and recombine on the wall) and energy needed for electrons $\mathrm{R}-\mathrm{D}$ emission (Vext is the tungsten extraction potentiel). As the space charge zone is not computed here, $V_{\text {cat }}$ the corresponding potential drop is supposed to be $5 \mathrm{~V} / 10$, $16,17 /$.

(3) Arc column boundary conditions $/ 21,22 /$ :

A cathode wall heat flux condition is deternined from the cathode sheath modelling on the $M$ points.

On the anode wall, the experimental temperature distribution $/ 2,23 /$ is imposed, the electrical potential is a result of the computation, because total current arc intensity is fixed (at $200 \mathrm{~A}$ for example).

On the external boundary atmospheric pressure is imposed, and the normal stress tensor component is supposed to be equal to 0 where no argon flow is imposed. NEUMANN's conditions are applied for electric potential and temperature (except when the flow enters the computational domain, then $\mathrm{T}$ is supposed to be $\operatorname{cold} \approx 1000 \mathrm{~K}$ ).

4- NUMERICAL METHODS.

A two-dimensional but axisymetric finite differences code Mélodie developed at the Laboratoire National d'Hydraulique for thermal-hydraulics analysis $/ 21,22 /$ and based on fractional steps, was adapted for these calculations. The numerical scheme is implicit and has been written according to an incremental formulation. In order to avoid numerical diffusion, the advection equation is solved by a two-dimensional characteristics 
method. Accurate treatment of the wall grid nodes allows to describe oblique walls with respect to the orthogonality of grid. The electrode sheath one-dimensional subgrid model is computed in the last mesh near the cathode wall. The equations are solved by a GAUSS implicit method. Temperatures are coupled by the collisions terms on an implicit scheme.

\section{5- RESULTS AND DISCUSSION.}

The calculations were first performed for a free burning argon arc at atmospheric pressure : the total current intensity is imposed at 200 amperes and the arc dimension between anode and cathode is $1 \mathrm{~cm}$ long. The cathode is made of tungsten. Both arc column and cathode temperature fields are represented on figure 2 with two different scales. We obtain a good simulation of the global arc configuration, and especially of arc constriction and high temperature gradient which takes place at the cathode tip. The important arc column gas flow due to LORENTZ forces is represented on figure $3:$ the plasma velocity reaches $350 \mathrm{~m} / \mathrm{s}$ near the cathode tip. The argon plasma is then transferred to the anode. The cathode temperature is also realistic, even if the tungsten boiling temperature is reached at the cathode tip. Temperature profile on the arc axis [fig. 4] shows a good agreement with experimental values $/ 2 /$. Realistic values and evolution of electrical potential and current density are also found.

Figures 5 to 7 give subgrid model results for one cathode wall mesh located near the cathode tip : temperatures, and number densities (log 10 scale) are first plotted. The thermal non-equilibrium between heavy particles and electrons is clearly represented on figure 5. The electronic temperature stays nearly constant in the sheath, in connection with the current continuity, while heavy particles temperature goes down near the wall because of the heat transferred by thermal conduction to the cathode and then simulate the high temperature gradient appearing normally in the cathode sheath. Electrons number density is very high in hot ionized zone, but decreases near the wall [fig. 6] while atoms number density (and also reaction rate) increases. Realistic current densities results are also obtained : jiy is negligible compared to jey in most of the sheath, but because of particles diffusion it becomes more important near the cathode.

In figure 7 are represented electrons temperatures equations terms (log10 scale). The electrons energy mainly sustained by JOULE effect and equilibrated by conductive and convective transport in the highly ionized zone is used for ionization process near the wall. The elastic collision transfer of energy negligible for electrons is the principal energy sink for heavy particles.

For the transferred arcs [275 $A$ and $2.73 \mathrm{~cm}$ on figures 8 to 10 and $280 \mathrm{~A}$ and $5.06 \mathrm{~cm}$ on figure 11] the results have globally the same characteristics. We find that electric potential increases with the arc length (for ex $11 \mathrm{~V}$ for $200 \mathrm{~A} / 1 \mathrm{~cm}$ and $26 \mathrm{~V}$ for $275 \mathrm{~A} / 5.06 \mathrm{~cm}$ ); we notice that electrodes potential drops appearing in space charge zones are not included. It would explain why the value seems to be smaller than corresponding measurements $12,23 /$. Some radial temperature profiles (one on figure 9) show a disagreement between calculated and measured data especially on the arc edges where LTE assumption has to be questionned. But experimental measures are rather characteristic of electronic temperature and calculation is rather characteristic of heavy particles temperature. Transferred arcs velocities fields show a recirculating zone near the cathode due to argon injection [fig. 10].

\section{CONCLUSION}

This modelling of high intensity laminar arcs consists in a two-dimensional coupled resolution of electromagnetic and thermodynamic equations in the arc column with the assumption of Local Thermodynamic Equilibrium. In order to obtain accurate boundary conditions for the global arc column computation, a onedimensional non-equilibrium subgrid model is developed near the cathode wall related to global arc and cathode heat transfer computations. Both global and subgrid model results for free burning or transferred arcs zorrespond to a realistic configuration of high intensity arcs : temperatures in the arc column are in good agreement with measurements. Non-equilibrium temperatures obtained in the subgrid model give good flux boundary conditions at the cathode. With our coupled model we are now able to calculate laminar high intensity arcs without any assumption for the cathode boundary condition.

In order to give better predictions and to get rid of all parameters, the space charge zone in the electrode subgrid model would have to be taken into account. The anode boundary layer computation (treated by the same nodelling) will allow to extend the applications domain of this electric are modelling. 
/6̆/ DEVOTO Physics of fluids, vol. $16 \mathrm{n}^{\circ} 5$ (p 616) 1973.

77/ Sheerbrooke University Int. Report Thermodynamic and transport prop. of Argon, $\mathrm{N}_{2}$ and $\mathrm{O}_{2} 1984$.

18/ VARGAFTIK Tables on the thermo-physical prop. of liquid and gases 1975.

9/ Club EDF arc électrique (éditions du CNRS) L'arc électrique et ses applications 1984.

/10/ HSU, PFENDER J. Appl. Phys., vol. 54 nº (p 3818) 1983.

/11/ DINULESCU, PFENDER J. Appl. Phys., vol. 51 n$^{\circ} 6$ (p 3149) 1980.

112/ LEE, GREENWOOD, BREINGAN Proc. 7th Int. Conf. on ionization phenomena in gases Gradwenska Knjega, Beograd Yugoslavia (p 670) 1963.

/13/MTTCHNER, KRUGER Partially ionized gases (Wiley Interscience Edition) 1973.

/14/ GRAVES, JENSEN IEEE Transact. on Plasma Sc. vol. PS 14 n² (p78) 1986.

/15/DELALONDRE, SIMONIN Rapport EDF (HE44/88.38) 1988.

/16/ DELALONDRE, SIMONIN Rapport EDF (HE44/89.30) 1989.

117/DELALONDRE Thesis (Université de Rouen) 1990.

/18/ HOFFERT, LIEN Physics of Fluids, vol $10 \mathrm{n}^{\circ} 8$ (p 1769) 1967.

/19/DELCROIX Physique des plasmas (DUNOD) 1963.

20/POTAPOV High Temperature, vol $4 \mathrm{n}^{\circ} 1$ (p 48) 1966.

21/ SIMONIN, ROBINSON, BARCOUDA Proc. 22nd IARH Congress. Lausanne Aug.31-Sept.4 1987

R2/ VIOLLET Nuclear Engineering and Design 99 North Holland (p365) 1987.

123/ COUDERT, GRMMAUD Convention d'étude EDF-Universite LIMOGES rapport EDF HE44/89. 1989.

\section{RESULTS}

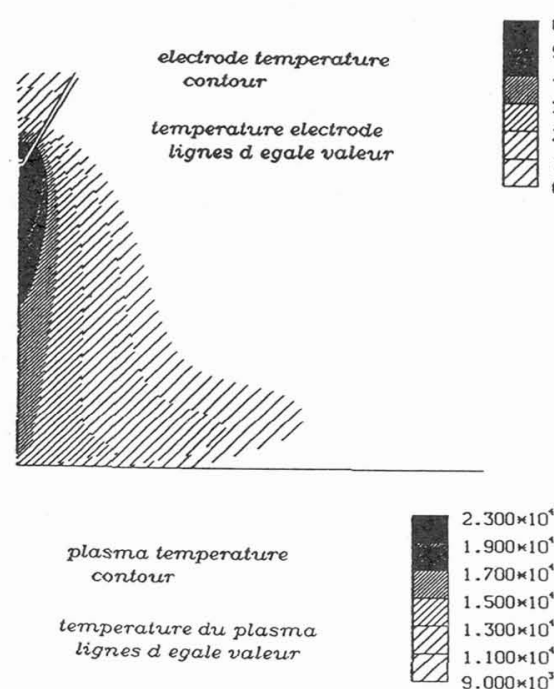

figure 2
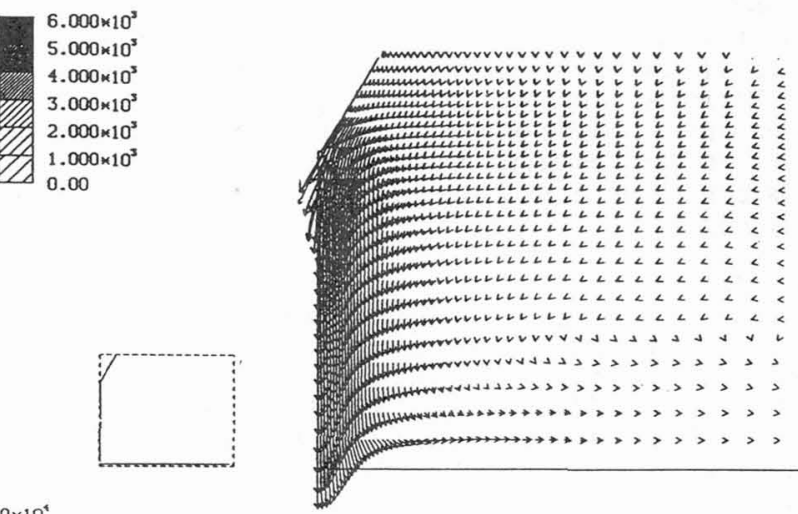

melodie
results

INH velocity field

vectors $\longrightarrow 28 \mathrm{~m} / \mathrm{s}$

champcie vitesse en $\mathrm{m} / \mathrm{s}$

vecteurs

figure 3

$200 \mathrm{~A}$ and $1 \mathrm{~cm}$ FREE BURNING ARC RESULTS

RESULTATS POUR UN ARC LIBRE DE 200 A ET $1 \mathrm{~cm}$ DE LONG 


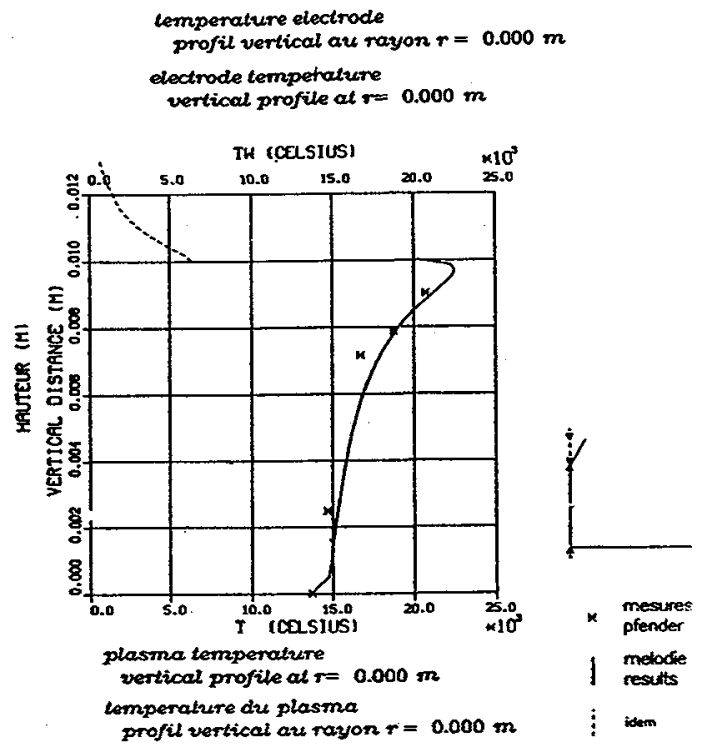

figure 4

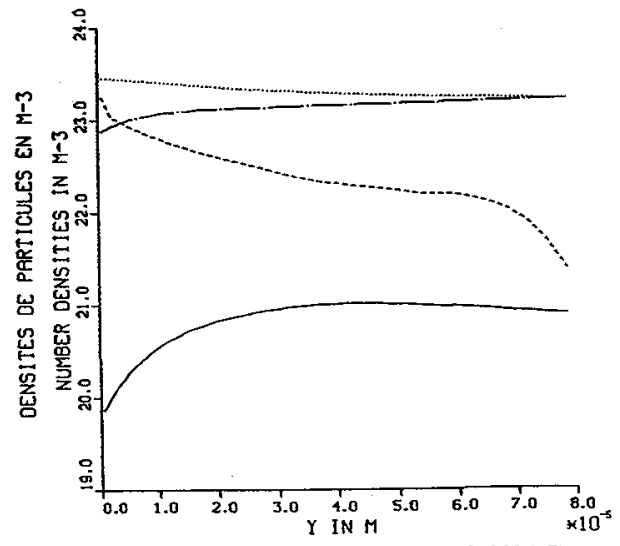

ORDONNEE DU MAILLAGE UNIDIMENSIONNEL Na (SFAR EQUILIBRIUTi) (A L EOUILJBRE OE SAHA

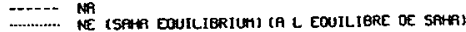

CATHODE SHEATH RESULTS FOR $P(I=2, J=36)$ COUCHE CATHODIQUE AU POINT $\mathrm{P}(\mathrm{I}=2, \mathrm{~J}=36)$

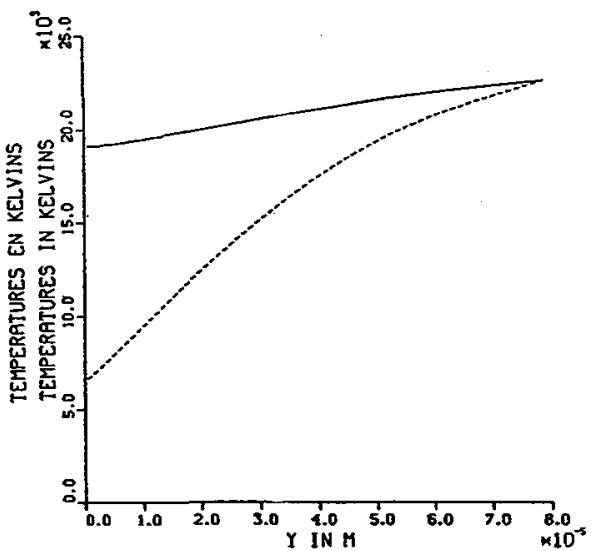

ORDONNEE OU MAILLREE UNIOIMENSIONNEL

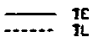

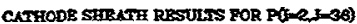

COUCHE CATHODIQUE AU PONT $\mathrm{P}(\mathrm{I}=2, \mathrm{~J}=36)$

figure 5

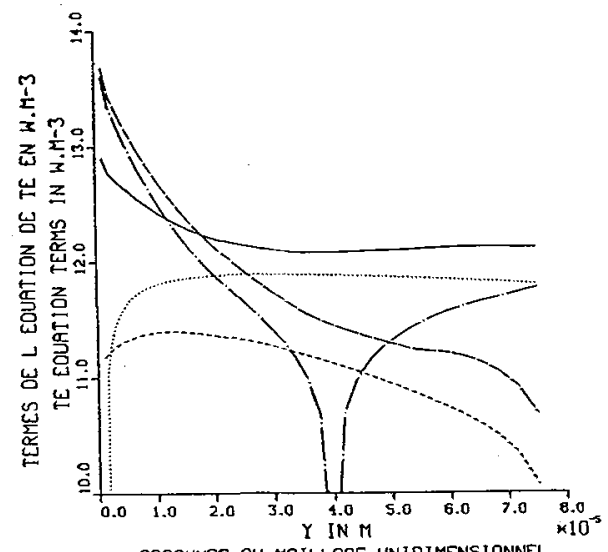

QROONNEE DU MAILLAGE UNIOIMENSIONNEL

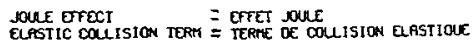

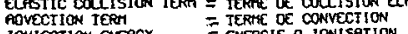

IONISATION ENERGY

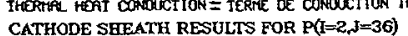
COUCHE CATHODIQUE AU POINT $P(l=2, \mathrm{~J}=36)$

figure 6

figure 7

$200 \mathrm{~A}$ and $1 \mathrm{~cm}$ FREE BURNING ARC RESULTS

RESULTATS POUR UN ARC LIBRE DE 200 A ET $1 \mathrm{~cm}$ DELONG 

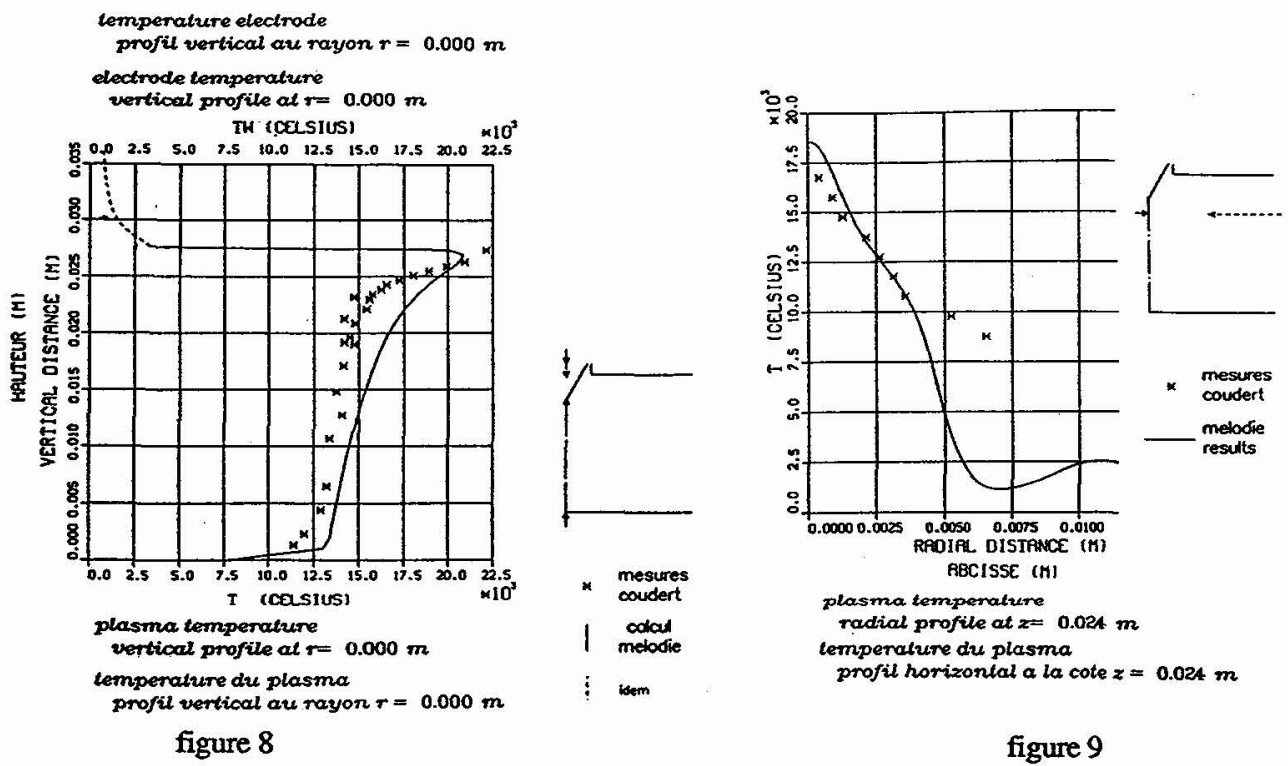

$275 \mathrm{~A}$ and $2.73 \mathrm{~cm}$ TRANSFERRED ARC RESULTS

RESULTATS POUR UN ARC TRANSFERE DE 275 A ET $2,73 \mathrm{~cm}$ DE LONG

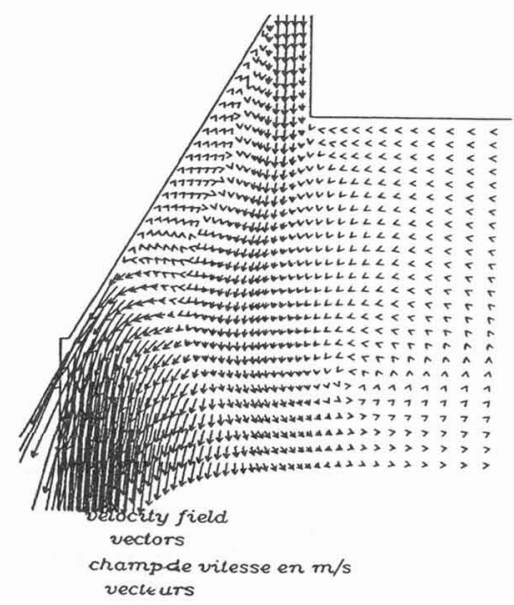

figure 10

$275 \mathrm{~A}$ and $2.73 \mathrm{~cm}$ TRANSFERRED ARC RESULTS RESULTATS POUR UN ARC TRANSFERE

DE 275 A ET 2,73 cm DE LONG

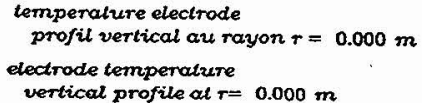

vertical profile at $\mathrm{T}=0.000 \mathrm{~m}$

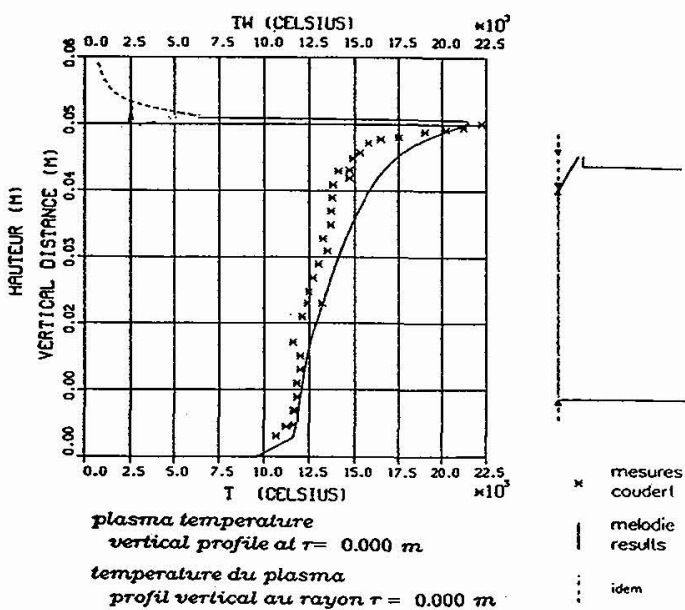

figure 11

$280 \mathrm{~A}$ and $5.06 \mathrm{~cm}$ TRANSFERRED ARC RESULTS RESULTATS POUR UN ARC TRANSFERE DE 280 A ET $5,06 \mathrm{~cm}$ 